\title{
Key developments in stem cell therapy in cardiology
}

\section{Ivonne H Schulman \& Joshua M Hare*}

A novel therapeutic strategy to prevent or reverse ventricular remodeling, the substrate for heart failure and arrhythmias following a myocardial infarction, is the use of cell-based therapy. Successful cell-based tissue regeneration involves a complex orchestration of cellular and molecular events that include stem cell engraftment and differentiation, secretion of anti-inflammatory and angiogenic mediators, and proliferation of endogenous cardiac stem cells. Recent therapeutic approaches involve bone marrowderived mononuclear cells and mesenchymal stem cells, adipose tissue-derived stem cells, cardiac-derived stem cells and cell combinations. Clinical trials employing mesenchymal stem cells and cardiac-derived stem cells have demonstrated efficacy in infarct size reduction and regional wall contractility improvement. Regarding delivery methods, the safety of catheter-based, transendocardial stem cell injection has been established. These proof-of-concept studies have paved the way for ongoing pivotal trials. Future studies will focus on determining the most efficacious cell type(s) and/or cell combinations and the mechanisms underlying their therapeutic effects.

KEYWORDS: cardiac stem cell - cell transplantation - heart failure - ischemic heart disease - mesenchymal stem cell - myocardial infarction

Ischemic heart disease affects an estimated 16.3 million Americans and is a leading cause of heart failure as well as cardiovascular mortality, accounting for approximately one in six deaths in the USA [1]. Over the past half-century, advances in risk factor modification and pharmacological and interventional therapeutic approaches have dramatically improved the quality and quantity of life of patients with ischemic heart disease. However, existing therapeutic strategies do not directly reverse the scar formation or progressive ventricular remodeling that follows a myocardial infarction (MI), a process that eventually leads to ventricular dysfunction and arrhythmias. Stem cell therapy has emerged as a strategy aimed at preventing or reversing myocardial injury and promoting cardiac tissue regeneration (FIGURE $\mathbf{1}$ ).
Preclinical models of ischemic heart disease employing large animals have been instrumental in advancing phenotypic and mechanistic insights underlying stem cell therapy, as well as the safety and efficacy of various methods of cell delivery and usefulness and precision of diverse imaging modalities to assess therapeutic efficacy [2-4]. Regarding the types of stem cells, embryonic stem cells (ESCs) can differentiate into all adult cell types and have been shown to have the potential for cardiac regeneration in animal models. However, ethical, legal, biological [5] and immunologic [6] issues have hindered their use in human trials. An attractive alternative to ESCs is the programming of adult somatic cells into ESC-like, induced-pluripotent stem cells [7] or induced cardiomyocytes [8]. These approaches have only recently started to be investigated clinically and the reproducibility, durability and safety of human cell reprogramming and genetic-engineering strategies remain the subject of investigation $[9,10]$. Nevertheless, the cardiovascular stem cell field has rapidly advanced and now numerous adult stem cell sources, including bone marrow-derived mononuclear cells (BMMNCs) [2,11-16], mesenchymal stem cells (MSCs) $[2,17]$, adipose tissue-derived stem cells [18] and cardiac-derived stem cells [19,20], are under clinical evaluation. It has become evident that the mechanisms underlying the therapeutic strategy of stem cell transplantation involves an orchestration of events including reduction of cardiac cell death and fibrosis, as well as stimulation of neovascularization and endogenous cell proliferation. With regards to MSCs, existing mechanistic studies support the importance of the release

Ivonne H Schulman, Interdisciplinary Stem Cell Institute, University of Miami Miller School of Medicine, Miami, FL, USA; and Nephrology-Hypertension Section, Miami Veterans Affairs Healthcare System, Miami, FL, USA

*Author for correspondence: Joshua M Hare, Interdisciplinary Stem Cell Institute, University of Miami Miller School of Medicine, Miami, FL, USA; Tel.: +1 305243 1999; Fax: +1 305243 3906; jhare@med.miami.edu 
of trophic, anti-inflammatory and immunomodulatory factors in addition to cell engraftment, differentiation and, notably, stimulation of endogenous cardiac stem cell (CSC) recruitment and differentiation [21]. This enhanced understanding of phenotypic response and mechanistic appreciation of the underpinnings of stem cell therapy can be harnessed for improved trial design, as well as for development of newer generations and combinations of stem cell products that have greater efficacy and sustainability (durability) $[4,22]$. The growing human phenotypic data from recent and ongoing clinical trials supports the notion that stem cell therapy is safe and has the capacity for repair of cardiac structure as well as restoration of cardiac function [4,17]. This article reviews the most recent developments in the clinical use of stem cells as a therapeutic strategy for cardiac structural and functional repair in acute and chronic ischemic heart disease.

\section{Recent developments \\ Acute MI}

Several studies over the past decade have tested intracoronary bone marrow infusions in patients with acute MI (TABLE 1). In the TOPCARE-AMI trial, patients with acute $\mathrm{MI}$ received an intracoronary infusion of ex vivo expanded BMMNCs or culture-enriched endothelial progenitor cells derived from peripheral blood MNCs [11]. The 5-year results demonstrated the long-term safety of intracoronary delivery of autologous BMMNCs in acute MI and, notably, the sustainability of the left ventricular

\section{Figure 1. Translational development of novel clinical therapies for heart} disease.

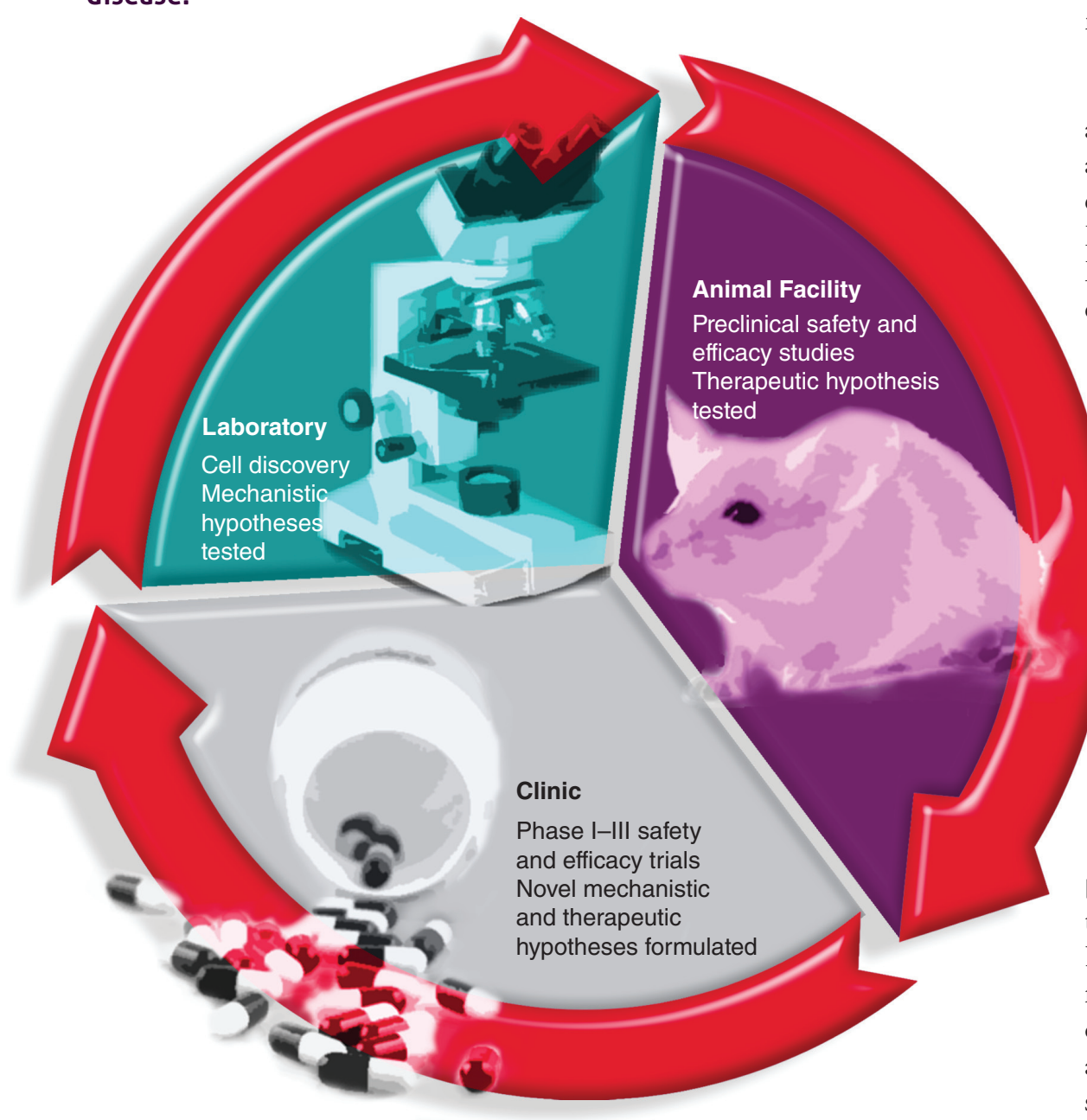

(LV) ejection fraction (LVEF) improvement in the treated group [11]. Most recently, a meta-analysis of 50 studies (2626 patients) confirmed the idea that this strategy prevents remodeling by reducing infarct size and LV chamber enlargement and that these benefits persisted during long-term follow-up [23]. Importantly, this meta-analysis confirmed a long-observed clinical benefit that is out of proportion to increases in cardiac function: BMMNC therapy reduced the incidence of death, recurrent MI and stent thrombosis in patients with ischemic heart disease. This evaluation strongly supports the soon-to-start BAMI trial (NCT01569178). This is a multinational, randomized, controlled, Phase III study that will investigate whether intracoronary infusion of autologous BMMNCs is safe and reduces all-cause mortality in patients with reduced LVEF (EF $\leq 45 \%)$ after successful reperfusion for acute $\mathrm{MI}$.

Pharmacologicandgenetic approaches are also under investigation with the aim of enhancing the therapeutic efficacy of cell-based therapy [9,10] . For instance, the Phase II clinical trial ENACT-AMI will investigate the efficacy and safety of autologous EPCs and autologous EPCs transfected with human endothelial nitric oxide synthase (NCT00936819).

Two clinical trials, one ongoing and one completed, are testing the impact of cell therapy timing on therapeutic potential. The ongoing Phase II trial developed by the Cardiovascular Cell Therapy Research Network, the TIME study, is comparing the safety and efficacy of intracoronary delivery of BMMNCs at 3 and 7 days post-MI in patients with ST-segment elevation [16]. On the other hand, the LateTIME trial investigated whether delaying BMMNC delivery for 2-3 weeks following MI and primary percutaneous coronary intervention improves global and regional LV function [13,14]. No significant changes between baseline 
and 6-month measures were observed in LVEF and wall motion in the infarct and border zones, as measured by cardiac MRI, in the BMMNC group compared with placebo. These findings indicate that the 2-3-week post-MI time-point may exceed the therapeutic window of intracoronary BMMNC therapy.

There is growing evidence that cell dose impacts therapeutic potential. In a randomized, controlled, open-label study, infarct-related artery infusion of $\mathrm{CD} 34^{+}$cells in patients with acute MI (AMR-01; NCT00313339), patients underwent infarct-related artery infusion of autologous bone marrow-derived $\mathrm{CD} 4^{+}$cells after ST elevation $\mathrm{MI}$ at a median of 8.3 days after coronary stenting [24]. Three dose levels were investigated in cohorts of five patients each. CD $34^{+}$cells are hematopoietic stem cells that have been shown to improve perfusion and function in myocardial and limb ischemia models by stimulating neovascularization directly through endothelial lineage differentiation and indirectly through the secretion of proangiogenic factors. This small, doseescalation pilot study reported that improved perfusion and infarct size reduction correlated with the quantity and mobility of the infused CD $34^{+}$cells.

With regard to other cell types and sources, the current evidence supporting the use of MSCs as a cellbased therapeutic for ischemic heart disease include ease of accessibility for isolation, the enormous expansion potential in culture, presumptive plasticity, immunomodulatory properties, potential as an allogeneic cell therapeutic, paracrine-mediated effects, homing and migratory behavior to sites of tissue injury, and ethical considerations. Of particular clinical interest is the potential use of allogeneic MSCs, which would preclude the need for the patients' bone marrow aspiration and the timely culture expansion of their MSCs. In this regard, bone marrowderived allogeneic MSCs (Prochymal ${ }^{\circledR}$; Osiris Therapeutics, Inc.) were recently investigated in a Phase II, 220 patient study in the setting of acute MI with depressed EF. It was preliminarily reported by Osiris [Unpublished Data] that a single intravenous infusion of either Prochymal or placebo within 7 days of an acute heart attack significantly reduced cardiac hypertrophy, stressinduced ventricular arrhythmia, heart failure and rehospitalization for cardiac complications compared with patients receiving placebo.

\section{Table 1. Recently published stem cell therapy clinical trials for ischemic heart disease.}

\begin{tabular}{|c|c|c|c|c|c|}
\hline Trial & $\begin{array}{l}\text { Year } \\
\text { reported }\end{array}$ & $\begin{array}{l}\text { Type of } \\
\text { trial }\end{array}$ & $\begin{array}{l}\text { Patients } \\
\text { (n) }\end{array}$ & Cell type & Ref. \\
\hline $\begin{array}{l}\text { LateTIME } \\
\text { Randomized, controlled, double-blind pilot trial evaluating the } \\
\text { safety and effect of intracoronary administration of BMMNCs 2-3 } \\
\text { weeks following acute myocardial infarction }\end{array}$ & (2011) & $\begin{array}{l}\text { Phase II } \\
\text { RCT }\end{array}$ & 87 & $\begin{array}{l}\text { Autologous } \\
\text { BMMNCs }\end{array}$ & [13] \\
\hline $\begin{array}{l}\text { TOPCARE-AMI } 5 \text {-year results } \\
\text { First randomized study investigating the effects of intracoronary } \\
\text { infusion of circulating or bone marrow-derived progenitor cells in } \\
\text { patients with successfully reperfused acute myocardial infarction }\end{array}$ & (2011) & $\begin{array}{l}\text { Phase I } \\
\text { RCT }\end{array}$ & 55 & $\begin{array}{l}\text { Autologous } \\
\text { BMMNCs }\end{array}$ & [11] \\
\hline $\begin{array}{l}\text { FOCUS-CCTRN } \\
\text { Randomized, double-blind, placebo-controlled study investigating } \\
\text { the efficacy of transendocardial delivery of BMMNCs in patients } \\
\text { with chronic ischemic cardiomyopathy }\end{array}$ & (2012) & $\begin{array}{l}\text { Phase II } \\
\text { RCT }\end{array}$ & 92 & $\begin{array}{l}\text { Autologous } \\
\text { BMMNCs }\end{array}$ & [15] \\
\hline $\begin{array}{l}\text { TAC-HFT (ongoing) } \\
\text { Randomized, double-blinded, placebo-controlled trial evaluating } \\
\text { the safety and efficacy of percutaneous delivery with a } \\
\text { transendocardial catheter delivery system of autologous bone } \\
\text { marrow-derived MSCs or BMMNCs in patients with chronic } \\
\text { ischemic cardiomyopathy and heart failure secondary to } \\
\text { myocardial infarction }\end{array}$ & (2011) & $\begin{array}{l}\text { Phase I/II } \\
\text { RCT }\end{array}$ & 8 & $\begin{array}{l}\text { Autologous MSCs } \\
\text { BMMNCs }\end{array}$ & {$[2]$} \\
\hline $\begin{array}{l}\text { SCIPIO (ongoing) } \\
\text { Randomized, placebo-controlled study investigating the safety of } \\
\text { intracoronary cardiac stem cell therapy in patients with chronic } \\
\text { ischemic cardiomyopathy }\end{array}$ & (2011) & $\begin{array}{l}\text { Phase I } \\
\text { RCT }\end{array}$ & 23 & $\begin{array}{l}\text { Autologous c-kit }{ }^{+} \\
\text {cardiac stem cells }\end{array}$ & [19] \\
\hline $\begin{array}{l}\text { CADUCEUS } \\
\text { Randomized, placebo-controlled, dose-escalation study of the } \\
\text { safety and efficacy of intracoronary delivery of cardiosphere- } \\
\text { derived stem cells in patients with ischemic cardiomyopathy and a } \\
\text { recent myocardial infarction }\end{array}$ & (2012) & $\begin{array}{l}\text { Phase I } \\
\text { RCT }\end{array}$ & 25 & $\begin{array}{l}\text { Autologous } \\
\text { cardiosphere- } \\
\text { derived stem cells }\end{array}$ & [20] \\
\hline
\end{tabular}


In terms of the source of MSCs, there is also preclinical evidence for the therapeutic potential of adipose tissuederived MSCs [18], but no clinical trials have been initiated yet in acute MI patients. However, the noncultured adipose stromal vascular fraction, a heterogeneous population of cells with multilineage differentiation potential, is being tested in two clinical trials. The first study, the APOLLO trial (NCT00442806), is a double-blind, placebo-controlled trial evaluating the safety (defined as major adverse cardiac and cerebral events at 6 months) of intracoronary infusion of autologous adipose-derived stem and regenerative cells in acute MI patients after successful revascularization. A lipoaspirate is obtained by liposuction under local anesthesia and the adiposederived stem and regenerative cells are isolated using the Celution ${ }^{\mathrm{TM}}$ System (Cytori Therapeutics). The preliminary data, reported at the 7th International Symposium on Stem Cell Therapy and Cardiovascular Innovation, Madrid, Spain, in May 2010, showed improvement in LVEF, reduction in infarct size, and improvement in myocardial perfusion [25]. A Phase II/III trial the ADVANCE study (NCT01216995) has been initiated to further evaluate the efficacy of this approach, defined as reduction in infarct size at 6 months.

\section{- Chronic ischemic cardiomyopathy $\&$ heart failure}

The FOCUS-CCTRN is a Phase II trial in patients with chronic ischemic cardiomyopathy that investigated the 6-month efficacy of transendocardial delivery of BMMNCs on myocardial function and perfusion [15]. Although the study showed no significant effect on LV end-systolic volume, maximal oxygen consumption or myocardial perfusion, exploratory analyses demonstrated significant improvement in stroke volume and LVEF, which correlated with higher bone marrow $\mathrm{CD} 34^{+}$and $\mathrm{CD}_{133^{+}}$progenitor cell counts. These findings support the notion that certain bone marrow-derived cell populations may provide a greater regenerative benefit and thereby determine clinical efficacy. In this regard, the ACT34CMI (Adult Autologous CD34+ Stem Cells; NCT00300053) investigators conducted a double-blind, randomized, Phase II clinical trial to evaluate the safety and efficacy of intramyocardial injections of autologous $\mathrm{CD} 34^{+}$cells in patients with refractory chronic myocardial ischemia on maximal therapy who were not suitable candidates for conventional revascularization [26]. Cell therapy was associated with significant improvements in angina frequency and exercise tolerance at both 6 and 12 months compared with placebo treatment, supporting the conduct of larger-scale studies to verify these beneficial effects in patients with refractory angina. Similarly, a smaller randomized, controlled clinical trial in patients with dilated cardiomyopathy reported that intracoronary infusion of $\mathrm{CD} 34^{+}$cells was associated with an increase in LVEF and 6-min walk distance and a lower secondary end point of 1-year mortality or heart transplantation [27].

Our group has shown in a preclinical large animal model of chronic MI that surgical injection of bone marrowderived autologous as well as allogeneic MSCs results in a reduction in infarct size and an increase in regional myocardial contractility [21,28,29]. These findings are being translated into improvements in clinical outcomes. The results from the first eight patients of the TAC-HFT trial have recently been published [2]. This Phase I/II, randomized, doubleblind, placebo-controlled trial evaluated the safety and efficacy of percutaneous delivery with a transendocardial catheter delivery system of autologous bone marrow-derived MSCs or BMMNCs in patients with chronic ischemic cardiomyopathy and heart failure secondary to MI. The first eight patients (four received MSCs and four received BMMNCs) demonstrated decreased infarct size and improved regional contractility. Moreover, it was noted that improvements in regional function observed at 3 months after cell therapy predicted the degree of LV reverse remodeling after 12 months. Importantly, the findings from our preclinical studies as well as this clinical study suggest that the selection of end points, such as infarct size and regional contractility, which can be directly measured and accurately reflect clinical outcomes, could represent more suitable measures of cell therapy efficacy than global LVEF, which most cell therapy trials have used as the primary efficacy end point $[2,3]$.

In addition, our group is conducting two clinical trials comparing the safety and efficacy of bone marrow-derived allogeneic and autologous MSCs. The initial findings of the POSEIDON study (NCT01087996), the first direct randomized head-to-head comparison of autologous versus allogeneic MSCs delivered by transendocardial injection, will be presented as a late-breaking clinical trial at the American Heart Association Scientific Sessions in November 2012 [30]. A parallel, ongoing clinical trial, POSEIDON-DCM (NCT01392625), aims to establish the safety and efficacy of transendocardial autologous versus allogeneic MSC therapy in patients with nonischemic, dilated cardiomyopathy.

Currently, there is only one ongoing clinical trial using culture-expanded adipose tissue-derived MSCs, the MyStromalCell trial (NCT01449032). This double-blind, placebo-controlled trial in patients with chronic ischemic heart disease is investigating the efficacy and safety of intramyocardial delivery of VEGF-A $165^{-s t i m u l a t e d ~ a u t o l o g o u s ~}$ adipose tissue-derived MSCs to improve myocardial perfusion and exercise capacity and reduce symptoms. The PRECISE trial (NCT00426868), a randomized, controlled clinical trial using noncultured adipose stromal vascular fraction cells, tested the effect of intramyocardial delivery in patients 
with chronic ischemic cardiomyopathy. The preliminary data, reported at the 7th International Symposium on Stem Cell Therapy and Cardiovascular Innovation, showed a reduction in infarct size and an improvement in maximum oxygen consumption and exercise capacity [31].

Another extremely promising cell-based therapeutic for chronic ischemic cardiomyopathy and heart failure are cardiac-derived stem cells. Cardiac-derived stem cells under investigation include cells that express the SCF receptor c-kit (CD117) [32] and multicellular clusters named cardiospheres [33]. Both can be harvested from patient endomyocardial biopsies and expanded ex vivo to generate large numbers of autologous cells that can be delivered back to the patient $[33,34]$. Recently published results from the ongoing Phase I clinical trial, SCIPIO, demonstrated that intracoronary infusion of autologous c-kit ${ }^{+}$CSCs is safe and effective at improving LV systolic function and reducing infarct size in patients with heart failure (LVEF < 40\%) after MI who had undergone coronary artery bypass grafting [19]. Notably, LVEF significantly increased from $30.3 \pm 1.9$ to $38.5 \pm 2.8 \%(n=14)$ at 4 months after infusion of CSCs, whereas no change in LVEF was evident in the control patients $(n=7)$. There was evidence of an even greater effect at 1 year, with an increase in LVEF of $12.3 \pm 2.1$ EF units versus baseline $(n=8)$. The increase in LVEF was associated with an improvement in regional wall contractility in the infused LV regions as well as all the LV segments combined. Furthermore, infarct size (mean infarct weight assessed with cardiac MRI) decreased by $24 \%$ at 4 months and $30 \%$ at 1 year $(n=7)$. These dramatic initial results are highly encouraging and warrant further investigation in larger studies. On the other hand, the recently completed CADUCEUS trial [20] is a Phase I randomized clinical trial of cardiospheres as a cell-based therapeutic. A total of 25 patients with ischemic heart disease, successful percutaneous coronary revascularization, and LV dysfunction (mean baseline LVEF was $39 \pm 12 \%$ ) were randomized to receive infarct-related coronary artery infusion of cardiosphere-derived cells or standard care 1.5-3 months after MI. A reduction in scar mass $(28 \%$ by 6 months and $42 \%$ by 12 months) and an increase in viable heart mass, regional contractility and regional systolic wall thickening was observed 6 months following cell therapy, as assessed by cardiac MRI. However, in contrast to the study of cultureexpanded c-kit ${ }^{+}$CSCs, cardiospheres did not augment parameters of integrated cardiac performance such as LVEF, end-diastolic volume or end-systolic volume. The differences in clinical outcomes may be related to variability in study design, including the target patient population, delivery method, cell dose and CSC-specific characteristics. Nevertheless, the encouraging results from these two clinical trials provide rationale for larger randomized trials that will extend these observations to test whether cardiac-derived stem cell infusion produces sustainable clinical benefits in patients with ischemic heart disease.

\section{Future perspectives}

Although there has been significant progress in the clinical translation of cell therapy over the past decade, uncertainties remain regarding the most efficacious cell type, source and quantity, as well as route and timing of delivery. Adding to the complexity, there is growing evidence that stem cells harvested from patients do not produce the same benefit as those from healthy individuals [35]. Collectively, these issues highlight the need for further investigation of the mechanisms underlying stem cell survival, plasticity and function. In addition, pharmacologic and genetic strategies are being developed in an effort to improve stem cell survival, homing and engraftment, which will potentially translate into better clinical outcomes
[9,10,36-39]. Two novel and exciting possibilities are the combination of different stem cells [40] or of cell and gene therapy [9,10,36-39]. In addition, the discovery of microRNAs as regulators of cardiovascular biology and stem cell differentiation have made them attractive targets to optimize cell-based therapies [41].

One of the major challenges of cellbased therapy is the survival of cells after delivery into the recipient tissue microenvironment. Ischemia creates a hostile microenvironment due to locally expressed proinflammatory and proapoptotic cytokines inducing cell death. Various approaches to inhibit local inflammation and promote cell survival and tissue regeneration are being investigated, including preconditioning by in vitro incubation of stem cells with prosurvival factors, or transfection of stem cells with prosurvival or antiapoptotic genes prior to cell delivery [9,10,36-39].

\section{Combination cell therapy}

Based on our findings that MSCs interact with endogenous c-kit ${ }^{+}$CSCs via connexin-43 gap junctions and stimulate their proliferation and differentiation [21], we hypothesized that combination therapy may provide greater cardiacstructural and functional repair. Recently, this combination of cell types have demonstrated efficacy in eliciting a favorable remodeling response in preclinical models. A preliminary report in a porcine model of MI showed that the combination of MSCs and c-kit ${ }^{+}$CSCs is more effective at reducing infarct size and restoring cardiac function than either cell type alone [40]. These findings support the initiation of clinical trials in patients with chronic ischemic cardiomyopathy, which are currently in the planning phase.

\section{Novel in vivo differentiation \& imaging approaches}

Recent studies employing animal models of ischemic heart disease 
have reported the development of novel approaches to enhance in vivo differentiation of endogenous cells into cardiomyocytes [42]. Song et al. demonstrated that a cocktail of four transcription factors (GATA4, HAND2, MEF2C and TBX5) reprogrammed adult fibroblasts into cardiomyocytes in vitro [42]. Notably, using a retrovirus to deliver the transcription factors to the hearts of mice, they demonstrated that expression of these four transcription factors reprograms nonmyocytes to cardiomyocytes in vivo and attenuates cardiac dysfunction after MI. Although further studies in large animal models are required before translation into clinical trials, this is an exciting approach with potential for endogenous cardiac regeneration that

\section{Key points}

\section{Acute myocardial infarction}

- Intracoronary delivery of autologous bone marrow-derived mononuclear cells (BMMNCs) prevents remodeling after acute myocardial infarction (MI) by reducing infarct size and left ventricular chamber enlargement. BMMNC therapy also reduced the incidence of death, recurrent $\mathrm{MI}$ and stent thrombosis.

- A Phase Il study employing bone marrow-derived allogeneic mesenchymal stem cells (MSCs; Prochymal ${ }^{\circledR}$; Osiris Therapeutics, Inc.) in the setting of acute MI recently reported preliminary findings that an intravenous infusion of Prochymal within 7 days of an acute MI significantly reduced cardiac hypertrophy, stress-induced ventricular arrhythmia, heart failure and rehospitalization for cardiac complications.

- A Phase II/III safety and efficacy study of autologous adipose-derived stem and regenerative cells delivered via the intracoronary route in acute MI patients (ADVANCE Study) has been initiated.

\section{Chronic ischemic cardiomyopathy \& heart failure}

- The Phase II trial FOCUS-CCTRN investigated the efficacy of transendocardial delivery of BMMNCs in patients with chronic ischemic cardiomyopathy. Exploratory analyses showed an improvement in left ventricular ejection fraction that was associated with higher bone marrow $\mathrm{CD} 34^{+}$and $\mathrm{CD} 133^{+}$progenitor cell counts, suggesting that certain bone marrow cell populations may provide a greater regenerative benefit and determine clinical efficacy.

- Results from the first eight patients of TAC-HFT, a Phase I/II, randomized, double-blind, placebo-controlled trial, demonstrated the safety and efficacy of percutaneous delivery with a transendocardial catheter delivery system of autologous bone marrow-derived MSCs or BMMNCs in patients with chronic ischemic cardiomyopathy. The patients exhibited improved regional myocardial contractility and decreased infarct size, and the improvements in regional function observed at 3 months after cell therapy predicted the degree of reverse remodeling after 12 months.

- The POSEIDON study (NCT01087996), the first randomized head-to-head comparison of autologous versus allogeneic MSCs delivered by transendocardial injection, will be presented as a late-breaking clinical trial at the American Heart Association Scientific Sessions in November 2012.

- The ongoing MyStromalCell Trial is the first randomized, double-blind, controlled study investigating intramyocardial VEGF- $\mathrm{A}_{165}$-stimulated adipose tissue-derived MSCs.

\section{Cardiac-derived stem cells}

- The Phase I clinical trial SCIPIO demonstrated that intracoronary infusion of autologous c-kit ${ }^{+}$cardiac stem cells is safe and effective at improving left ventricular systolic function and reducing infarct size in patients with chronic ischemic cardiomyopathy.

- The CADUCEUS trial, a Phase I randomized clinical trial of cardiospheres as a cell-based therapeutic, demonstrated a reduction in scar mass and an increase in viable heart mass, regional contractility and regional systolic wall thickening at 6 months after cell therapy.

\section{Combination cell therapy}

- Preclinical studies showed that the combination of MSCs and c-kit cardiac stem cells is more effective at reducing infarct size and restoring cardiac function than either cell type alone, supporting the planned initiation of clinical trials in patients with chronic ischemic cardiomyopathy.

\section{Novel in vivo differentiation \& imaging approaches}

- In preclinical studies, a cocktail of four transcription factors (GATA4, HAND2, MEF2C and TBX5) reprogrammed adult fibroblasts into cardiomyocytes in vitro and in vivo and attenuated cardiac dysfunction after MI. Future studies in large animal models are required to investigate further the safety and efficacy of this novel approach for endogenous cardiac regeneration.

- In preclinical studies employing a large animal model of MI, sodium iodide symporter transgene imaging was shown to be a feasible approach to follow in vivo survival, engraftment and distribution of human induced pluripotent stem cell derivatives.

\section{Conclusion}

- Future studies investigating the use of cell-based therapy in ischemic heart disease will focus on determining the most efficacious and safe cell type(s) and/or cell combinations to use as well as how cell-cell interactions mediate the cardiac regenerative effects. 
would obviate the need for stem cell transplantation. Nevertheless, there are many additional benefits that cell therapy brings to bear, and the relative value of each approach will require future investigation.

Imaging approaches that allow for long-term monitoring of viable transplanted stem cells are necessary for the evaluation of novel cell-based therapies in preclinical and clinical studies. In a recent study, sodium iodide symporter transgene imaging was evaluated as an approach to follow in vivo survival, engraftment and distribution of human-induced pluripotent stem cell derivatives in a porcine model of MI [43]. This study demonstrated the feasibility of repeated long-term in vivo imaging of viability and tissue distribution of cellular grafts in large animals. In addition, it showed vascular differentiation and long-term engraftment of human induced pluripotent stem cells in a clinically relevant large animal model of MI.

\section{Conclusion}

In summary, cell-based therapy for ischemic cardiomyopathy and heart failure has emerged as a highly promising therapeutic approach that will expand the benefits obtained by current pharmacologic and revascularization approaches by directly reversing scar formation and promoting myocardial regeneration. The next stage of development for the clinical use of cell therapy should focus on investigating novel formulations, particularly the best cell type(s) and/or cell combinations to use and elucidation of the mechanisms by which various stem cells interact with host cells and/or each other and elicit their regenerative effects.

Financial \& competing interests disclosure

JM Hare is supported by NIH grants: RO1 HL094849, P20 HL101443, RO1 HL084275, RO1 HL107110, RO1 HL110737 and UM1 HL113460. JM Hare is listed on a patent for cardiac cell-based therapy, receives research support from Biocardia, is a Consultant to Kardia, and reports an equity interest in Vestion, Inc. IH Schulman has no conflict of interest that could influence this work. The authors have no other relevant affiliations or financial involvement with any organization or entity with a financial interest in or financial conflict with the subject matter or materials discussed in the manuscript apart from those disclosed.

No writing assistance was utilized in the production of this manuscript.

\section{References}

Papers of special note have been highlighted as: " of considerable interest

1 Roger VL, Go AS, Lloyd-Jones DM et al. Heart disease and stroke statistics - 2011 update: a report from the American Heart Association.Circulation 123(4), e18-e209 (2011).

2 Williams AR, Trachtenberg B, Velazquez $\mathrm{DL}$ et al. Intramyocardial stem cell injection in patients with ischemic cardiomyopathy: functional recovery and reverse remodeling. Circ. Res. 108(7), 792-796 (2011).

- TAC-HFT is the first randomized, double-blind, placebo-controlled trial investigating the safety and efficacy of transendocardial catheter delivery of autologous mesenchymal stem cells in patients with ischemic cardiomyopathy.

3 Suncion VY, Schulman IH, Hare J. Concise review: the role of clinical trials in deciphering mechanisms of action of cardiac cell-based therapy. Stem Cells Transl. Med. 2(1), 29-35 (2012).

4 Karantalis V, Balkan W, Schulman IH, Hatzistergos K, Hare JM. Cell-based therapy for prevention and reversal of myocardial remodeling. Am. J. Physiol. Heart Circ. Physiol. 303(3), H256-H270 (2012).
5 Blum B, Benvenisty N. The tumorigenicity of human embryonic stem cells. Adv. Cancer Res. 100, 133-158 (2008).

6 Zhu WZ, Hauch KD, Xu C, Laflamme MA. Human embryonic stem cells and cardiac repair. Transplant Rev. (Orlando) 23(1), 53-68 (2009).

7 Wernig M, Meissner A, Foreman R et al. In vitro reprogramming of fibroblasts into a pluripotent ES-cell-like state. Nature 448(7151), 318-324 (2007).

8 Ieda M, Fu JD, Delgado-Olguin P et al. Direct reprogramming of fibroblasts into functional cardiomyocytes by defined factors. Cell 142(3), 375-386 (2010).

9 Mushtaq M, Oskouei BN, Hare JM. Cell therapy for heart disease: to genetically modify or not, that is the question. Circ. Res. 108(4), 398-401 (2011).

10 Kanashiro-Takeuchi RM, Schulman IH, Hare JM. Pharmacologic and genetic strategies to enhance cell therapy for cardiac regeneration. J. Mol. Cell. Cardiol. 51(4), 619-625 (2011).

11 Leistner DM, Fischer-Rasokat U, Honold $\mathrm{J}$ et al. Transplantation of Progenitor Cells and Regeneration Enhancement in Acute Myocardial Infarction (TOPCARE-
AMI): final 5-year results suggest longterm safety and efficacy. Clin. Res. Cardiol. 100(10), 925-934 (2011).

12 Schaefer A, Zwadlo C, Fuchs M et al. Long-term effects of intracoronary bone marrow cell transfer on diastolic function in patients after acute myocardial infarction: 5-year results from the randomized-controlled BOOST trialan echocardiographic study. Eur. J. Echocardiogr. 11(2), 165-171 (2010).

13 Traverse JH, Henry TD, Ellis SG et al. Effect of intracoronary delivery of autologous bone marrow mononuclear cells 2 to 3 weeks following acute myocardial infarction on left ventricular function: the LateTIME randomized trial. JAMA 306(19), 2110-2119 (2011).

14 Hare JM. Bone marrow therapy for myocardial infarction. JAMA 306(19), 2156-2157 (2011)

15 Perin EC, Willerson JT, Pepine CJ et al. Effect of transendocardial delivery of autologous bone marrow mononuclear cells on functional capacity, left ventricular function, and perfusion in chronic heart failure: the FOCUSCCTRN trial. JAMA 307(16), 1717-1726 (2012).

16 Traverse JH, Henry TD, Vaughan DE et al. Rationale and design for TIME: a Phase II, 
randomized, double-blind, placebocontrolled pilot trial evaluating the safety and effect of timing of administration of bone marrow mononuclear cells after acute myocardial infarction. Am. Heart J. 158(3), 356-363 (2009).

17 Williams AR, Hare JM. Mesenchymal stem cells: biology, pathophysiology, translational findings, and therapeutic implications for cardiac disease. Circ. Res. 109(8), 923-940 (2011).

18 Mazo M, Arana M, Pelacho B, Prosper F. Mesenchymal stem cells and cardiovascular disease: a bench to bedside roadmap. Stem Cells Int. 175979 (2012).

19 Bolli R, Chugh AR, D'amario D et al. Cardiac stem cells in patients with ischaemic cardiomyopathy (SCIPIO): initial results of a randomised Phase 1 trial. Lancet 378(9806), 1847-1857 (2011).

III SCIPIO is the first clinical trial demonstrating the safety and efficacy of intracoronary infusion of c-kit ${ }^{+}$cardiac stem cells in patients with ischemic cardiomyopathy.

20 Makkar RR, Smith RR, Cheng K et al. Intracoronary cardiosphere-derived cells for heart regeneration after myocardial infarction (CADUCEUS): a prospective, randomised Phase 1 trial. Lancet 379(9819), 895-904 (2012).

-1- CADUCEUS is the first clinical trial demonstrating the safety and efficacy of intracoronary infusion of cardiospherederived cells in patients with ischemic cardiomyopathy.

21 Hatzistergos KE, Quevedo H, Oskouei BN et al. Bone marrow mesenchymal stem cells stimulate cardiac stem cell proliferation and differentiation. Circ. Res. 107(7), 913-922 (2010).

22 Williams AR, Hatzistergos KE, Carvalho $\mathrm{D}$ et al. Synergistic effect of human cardiac stem cells and bone marrow mesenchymal stem cells to reduce infarct size and restore cardiac function. Circulation 124(21), Abstract A13079 (2011).

23 Jeevanantham V, Butler M, Saad A, AbdelLatif A, Zuba-Surma EK, Dawn B. Adult bone marrow cell therapy improves survival and induces long-term improvement in cardiac parameters: a systematic review and meta-analysis. Circulation 126(5), 551-568 (2012).
24 Quyyumi AA, Waller EK, Murrow J et al. CD34(+) cell infusion after ST elevation myocardial infarction is associated with improved perfusion and is dose dependent. Am. Heart J. 161(1), 98-105 (2011).

25 Duckers E. Freshly adipose-derived stem cell in acute myocardial infarction. The APOLLO Trial. Presented at: Seventh International Symposium on Stem Cell Therapy and Cardiovascular Innovations. Madrid, Spain, 6-7 May 2010

26 Losordo DW, Henry TD, Davidson C et al. Intramyocardial, autologous $\mathrm{CD} 34^{+}$cell therapy for refractory angina. Circ. Res. 109(4), 428-436 (2011)

27 Vrtovec B, Poglajen G, Sever M et al. Effects of intracoronary stem cell transplantation in patients with dilated cardiomyopathy. J. Card Fail 17(4), 272-281 (2011)

28 Quevedo HC, Hatzistergos KE, Oskouei $\mathrm{BN}$ et al. Allogeneic mesenchymal stem cells restore cardiac function in chronic ischemic cardiomyopathy via trilineage differentiating capacity. Proc. Natl Acad. Sci. USA 106(33), 14022-14027 (2009).

29 Schuleri KH, Feigenbaum GS, Centola M et al. Autologous mesenchymal stem cells produce reverse remodelling in chronic ischaemic cardiomyopathy. Eur. Heart J. 30(22), 2722-2732 (2009).

30 Hare JM, Velazquez DL, Zambrano JP et al. Randomized comparison of allogeneic vs autologous mesenchymal stem cells in patients with ischemic cardiomyopathy. Circulation (Abstract, in press) (2012).

31 Perin E, Fernandez-Aviles, F. The PRECISE Trial. Presented at: Seventh International Symposium on Stem Cell Therapy and Cardiovascular Innovation. Madrid, Spain, 6-7 May 2010.

32 Beltrami AP, Barlucchi L, Torella D et al. Adult cardiac stem cells are multipotent and support myocardial regeneration. Cell 114(6), 763-776 (2003).

33 Smith RR, Barile L, Cho HC et al. Regenerative potential of cardiospherederived cells expanded from percutaneous endomyocardial biopsy specimens. Circulation 115(7), 896-908 (2007).

34 Barile L, Chimenti I, Gaetani R et al. Cardiac stem cells: isolation, expansion and experimental use for myocardial regeneration. Nat. Clin. Pract. Cardiovasc. Med. 4(Suppl. 1), S9-S14 (2007).
35 Giannotti G, Doerries C, Mocharla PS et al. Impaired endothelial repair capacity of early endothelial progenitor cells in prehypertension: relation to endothelial dysfunction. Hypertension 55(6), 1389-1397 (2010).

36 Fischer KM, Cottage CT, Wu W et al. Enhancement of myocardial regeneration through genetic engineering of cardiac progenitor cells expressing Pim-1 kinase. Circulation 120(21), 2077-2087 (2009).

37 Shujia J, Haider HK, Idris NM, Lu G, Ashraf M. Stable therapeutic effects of mesenchymal stem cell-based multiple gene delivery for cardiac repair. Cardiovasc. Res. 77(3), 525-533 (2008).

$38 \mathrm{Li}$ W, Ma N, Ong LL et al. Bcl-2 engineered MSCs inhibited apoptosis and improved heart function. Stem Cells 25(8), 2118-2127 (2007).

39 Cho J, Zhai P, Maejima Y, Sadoshima J. Myocardial injection with GSK-3betaoverexpressing bone marrow-derived mesenchymal stem cells attenuates cardiac dysfunction after myocardial infarction. Circ. Res. 108(4), 478-489 (2011).

40 Williams A, Hatzistergos K, Carvalho D et al. Synergistic effect of human cardiac stem cells and bone marrow mesenchymal stem cells to reduce infarct size and restore cardiac function. Circulation 124, A13079 (2011).

41 Chamorro-Jorganes A, Araldi E, Penalva LO, Sandhu D, Fernandez-Hernando C, Suarez Y. MicroRNA-16 and microRNA-424 regulate cell-autonomous angiogenic functions in endothelial cells via targeting vascular endothelial growth factor receptor-2 and fibroblast growth factor receptor-1. Arterioscler. Thromb. Vasc. Biol. 31(11), 2595-2606 (2011).

42 Song K, Nam Y-J, Luo X et al. Heart repair by reprogramming non-myocytes with cardiac transcription factors. Nature 485(7400), 599-604 (2012).

43 Templin C, Zweigerdt R, Schwanke K et al. Transplantation and tracking of human induced pluripotent stem cells in a pig model of myocardial infarction: assessment of cell survival, engraftment and distribution by hybrid SPECT-CT imaging of sodium iodide symporter trangene expression. Circulation 126(4), 430-439 (2012) 